of cooling clown was reached, because there was no water to form them; and no life conld have existed on the earth until it cooled down to the Intter temperature.

Thus we find in the Arctic regions, the following successive temperatures :-

$$
\begin{aligned}
& \text { I. }-212^{\circ} \mathrm{F} . \quad \ldots \quad \ldots \quad \text { Boiling water. }
\end{aligned}
$$

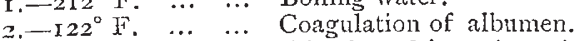

$$
\begin{aligned}
& \text { 3. }-68^{\circ} \mathrm{F} \text {. } \quad \ldots \quad \ldots \text { Triassic and jurassic periods. } \\
& \text { (Climate of Gulf of Mexico.) } \\
& \text { 4. - } 48^{\circ} \mathrm{F} . \quad \ldots \quad \ldots \quad \text { Miocene tertiary period. } \\
& \text { 5.- } 32^{\circ} \mathrm{F} . \quad \ldots \quad \ldots \quad \text { (Climate of Labrador.) } \\
& \text { 6. } \quad 0^{\circ} \mathrm{F} . \quad \ldots . \quad \ldots \quad \text { Present climate. }
\end{aligned}
$$

'The interval between the first and second corresponds to the azoic rocks; that between the second and third to the palæozoic rocks; and that between the third and fourth to the neozoic rocks, Now, although we do not know the coefficient that fixes the rate of cooling of the hot earth suspended in cold space, we know the law of such cooling, and can compare, by calculation, the proportions of the foregoing intervals of time with each other.

$$
\begin{aligned}
& \text { When this calculation is made we obtain :- }
\end{aligned}
$$

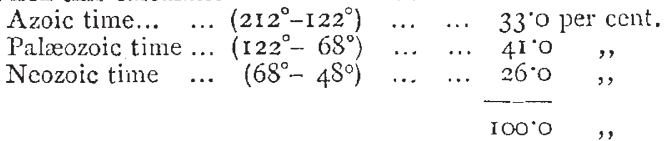

In my former note, iii. p. $545,^{1}$ I have given a table of tha approximate thicknesses of the several strata in Europe. That table was prepared, with the assistance of the late Prof. Phillips, many years ago, and is not as complete as it might be. I therefore sought the assistance of Prof. Edwarch Hull, Director of the Geological Survey of Ireland, and with his help I have con-

\begin{tabular}{|c|c|c|c|c|}
\hline \multicolumn{3}{|c|}{ Period. } & $\begin{array}{l}\text { From Theory of } \\
\text { Cooling Globe. }\end{array}$ & $\begin{array}{c}\text { From Maximum } \\
\text { Thickness of Strata. }\end{array}$ \\
\hline \multirow{2}{*}{\multicolumn{2}{|c|}{$\begin{array}{lll}\text { Azoic } & \ldots & \ldots \\
\text { Palzeozoic } & \ldots \\
\text { Neozoic } & \ldots & \ldots \\
& & \\
& & \\
& & \text { Total }\end{array}$}} & $\begin{array}{l}\cdots \\
\cdots \\
\cdots\end{array}$ & $\begin{array}{l}33^{\circ} \circ \text { per cent. } \\
4 I^{\circ} \circ,, \\
26.0 \quad,\end{array}$ & $\begin{array}{l}34.3 \text { per cent. } \\
42.5 \\
23 \cdot 2 \quad,,\end{array}$ \\
\hline & & $\ldots$ & $100^{\circ} 0$ & $100^{\circ} 0$ \\
\hline
\end{tabular}
structed an improved table.

Converting the maximum thicknesses recorded in that table into percentages, and comparing them with the percentages of time found from the theory of a cooling globe, we finct-

Scale of Geological Tine.

The agreement between these figures, derived from entircly independent sources, is remarkable, and tencls to justify the principle held by many geologists, that-

The proper relative measture of geological foriots is the mavimum thickness of the strata formed during those periods.

This is equivalent to supposing the rate of cleposition of strata to have been constant during the period containcel in the table, which is probable enough on other grounds; for, although the rock-making forces were greater when the heat was greater, it must be remembered that the land surfaces to be denuded were smaller, and that the sea bottoms, on which the débris was to be spread, were also greater. The calculation founded on the theory of the cooling globe cannot with safety be carried down to near the point of equilibrium temperature, which is the Fahrenheit zero (for the Arctic reoions under consideration); but we may, without risk, extend the calculation from $48^{\circ} \mathrm{F}$. to $32^{\circ} \mathrm{F}$; t that is, we may estimate the interval of time from the miocene tertiary epoch, when the Parry Islands and Northern Greenland enjoyed a Lombardic climate, to the epoch (probably long past) when those clistricts suffered a climate like that of Labracior, but better than that they now have.

The result of the calculation, when reduced to the same scale as that used in the table, is 32 per cent., a result, the importance of which will be better seen by the following propositions which flow from it :-

I. A greater interval of time now scparates as from the miocene tortiary epoch than that which acas occupied in froducing all the

$$
\text { I'roc. R. S., December } 20 \text { i } 877
$$

secondary and tertiary strata, from the triassic to the miocine cporth

2. The enormons interal of time that separates us from the mioccne epoch affords ample optortumety for the development of the gigantic mammals, which are commonly supposed to haic somezishat suddenly made their apperrance on all our contincuts, and to have disappeared as suddenly.

All the foregoing facts point to the conclusion that the present condition of the earth's surface is profoundly different from its condition in the seological periods when climates depended chiefly on the internal heat of the earth, and not on that of the sum, as at present.

The following table contains estimates of the number of years required by the several rivers to scrape off one foot from their respective rain-basins, and carry the materials to the sea, where it is spread out on the sea bottoms by ocean currents. The fioures are obtained by carefully measuring, at frequent intervals, the total discharge of water and the total weight of mud held in suspension. This weight of mud, reconverted into surface rock, must cover the entire rain-basin to a depth of one foot spread uniformly.

Rates of Denudation of Rain-Basins Lowered One Foot.

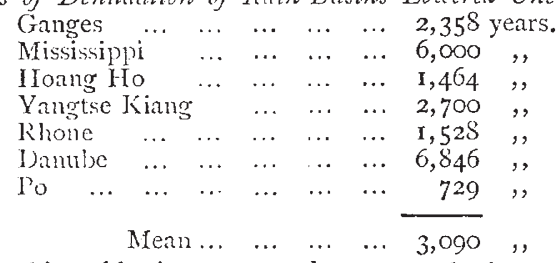

From this table it appears that atmospheric agencies are capable, at present, of lowering the land surfaces at the rate of one foot per 3,000 years; but since the sea bottoms are to the land surfaces in the proportion of 145 to 52 , the rate at which (uncler present circumstances) the sea bottoms are silted up, that is to say, the present rate of formation of strata, is one foot in 8,6 I6 years. If we admit (which I am by no means willing to do) that the manufacture of strata in geological times proceeded at ten times this rate, or at the rate of one foot for every $861 \cdot 6$ years, we have for the whole duration of geological time, down to the miocene tertiary epoch,

$86 \mathrm{I} \cdot 6 \times \mathrm{I}_{77}, 200=\mathrm{I} 52,675,000$ years. $^{1}$

To this must be added at least one-third, as before shown, to bring in the period from the Miocene Tertiary to the time when the Parry Islands and North Greenland had the climate of Labrador.

This gives for the whole cluration of geological time a minimum of tiw hundrat milions of y'ars.

\section{ACTION OF DRUGS ON THE LIVER 2}

PROF. RUTIIERIORD'S paper described the conclucling results of the long research undertaken by him on "The Biliary Secretion with Reference to the Actions of Cholarorucs." Ile pointed out the difficulties which had rendered it impossible for physicians to arrive at precise knowledge as to the actions of substances on the liver from observations on the human subject, and the imperative necessity for having recourse to experiments on animals, whereby some of the factors that complicate the case in the uninjured system may be eliminated, and definite knowledge regarding the action of agents on one of the most important organs of the body instituted for the vague guesses of twenty centuries. Several previous investigators had striven by experiments on animals to settle this question, but all had failed owing to the faulty character of the methods enployed. By a new and precise method of continuous collection of the bile, and measurement of the amount secreted every fifteen minutes-with a careful elimination of disturbing factors-the whole physiological pharmacology of the liver has been worked out by Prof. Rutherford-as far as it seems at present desirable to proceed. The actions of as many as forty-six substances on the bile-forming function of the liver have been investigated, and results of much in. portance for rational therapeutics obtained. Some of the I The coefficient 177,200 is the total number of feet of maximum thickiness of all the known stratified rocks.

2 Abstract of paper read at the Royal Socicty of Edinburgh on June 17 by Prof. Wm. Rutherford, F.R.S., Prof. Sir Wyville Thonson (in the absence of Sir $\mathrm{Vm}$. Thomson) in the chair. 
substances employed, viz., sodium salicylate, the benzoates, phytolaccin, physostigma, ciionymin, sanguinarin, ipecacuan, \&c., have not hitherto been known to stimulate the liver; and definite information has now been obtained regarding the influence of a number of other substances whose effects have been hitherto altogether doubtful. He has also proved that if a purgative agent has no direct stimulating power on the liver it diminishes the secretion of bile, and the importance of this fact is indicated. The results of the experiments which were performed on dogs are in complete harmony with every fact that has been perfectly ascertained in the lnman subject. The experiments with every substance supply a precision of knowledge regarding the effect of that substance on the liver which has not previously existed. In indicating the place for such experiments in medical science, Prof. Rutherford said :- "We all know how ex. cessively complicated the analysis of the effects of drugs becomes when they are administered to a bodily system distorted in its action by the effects of disease. Of necessity the infiuence of a drug upon a diseased state is the ultimatum of pharmacology; and every experiment upon a healthy bodily system, whether of man or animal, is merely ancillary to expcriments with the drug in disease. If we discover that a drug stimulates the healthy liver of a dog, we do not conclude that it must also stimulate the human liver in health, and still less do we conclude that it must have this action in disease. The experiments on the bealthy liver of the dog, on the normal and on the abnormal human liver, are three sets of experiments, closely related, but still distinct. The results of any one of the three series cannot be substituted for those of the other two. Each set of facts has its own proper place, and must be carefully kept there. When, therefore, we show by our physiological method of experiment that such a substance as sodium salicylate or sodium benzoate powerfully stimulates the liver of a dog, we do not for a moment say to the clinical observerYou will find that these things act thus in man; but we merely say this: Experiment with these agents on man, and tell us whether or not you find that they stimulate his liver, and tell us also in what diseased states you find the employment of this or of that substance most advantageous. The clinical experimentalist has a far more difficult task to discharge than the physiological investigator, and he urgently requires all the assistance that physiological methods can render him; and the more so because it is now admitted by all competent thinkers that the actions of medicinal agents in diseased conditions cannot be rightly unclerstood unless we also know their effects in a healthy condition of the bodily system." He further showed that although therapeutics can never be brought within the sphere of exact science, it is nevertheless very urgently our present business not to fold our hands in a despairing nihilism, but to search for every fact that can throw light on the function of every bodily organ, the nature of its diseased conditions, and the mamner in which it is influenced by medicinal agents in its normal and abnormal states; and all we desire is that those who don't comprehend our methods of procedure, although they are ever ready and eager to profit by its results, will, instead of throwing obstacles in our way, leave us to do what we can to alleviate not only the sufferings of human beings, but also those of animals.

1: At the conclusion of the paper Sir Robert Christison characterised the professor's communication as of the greatest im. portance, and as one which would hand his name down to a very distant future. The professor deserved the commendation of the Society for his courage in going on, in spite of a sentimental opposition, with his researches. He thought that the time would come when the public would wake up from the delusion in this regard in which it now was. Sir Wyville Thomson, in intimating the thanks of the Society to Prof. Rutherford, said that, in his opinion, if a man in a public position felt that he had knowledge and nerve sufficient to perform these experiments for lessening the suffering and prolonging the lives of men, even though they should involve a certain amount of suffering to the lower animals, he was not only entitled but was bound to peform them.

\section{SOCIETIES AND ACADEMIES \\ LONDON}

Royal Society, May I6.- "On the Spectra of Metalloids. Spectrum of Oxygen." By Arthur Schuster, Ph.D., F.R.A.S. Communicated by J. Clerk Maxwell, F.R.S., Professor of Txperimental Physics in the University of Cambriclge.
The many unexplained phenomena attending the passage of electricity througl gases will probably for some time to come occupy the attention of experimental physicists. It is desirable that the subject shoukd be approached from as many different sides as possible. One of our most powerful instruments of research is the spectroscope, but before it can be applied to the stucly in question we have to settle the chemical orisin of the different spectra, which we observe in vacumm tubes, and to discuss in what way such spectra are liable to change under different circumstances. I have chosen oxygen as a first subject of investigation. Though Plicker and Wiillner have, as far as their experiments went, accurately described the phenomena scen in oxygen tubes, the following contains much that is new, and will put some of the older facts on a firmer basis.

As some of the facts brought to light by the investigation bear directly on the question of double spectra, our knowledge on that point must be briefly referred to. We divide all known spectra into three orders-continuous spectra, channelled space spectra and line spectra. With regard to continuous spectra, it is shown that the older statement which limited them to liquid and solid bodies is no longer tenable. Most gases give contintous spectra Iong before they condense. Two theories of continuous spectra are noticed. The one considers that the vibrations of a molecule always tend to take place in a fixed period, but that the im pacts of other molecules may, when the pressture is great or in liquid and solid bodies, prevent complete oscillations taking place, and thus produce a continuous spectrum. The other theory considers that, when a gas condenses, molecular combina. tions take place, which make the molecular structure more com plicated, and may produce channelled space spectra or continuous spectra. According to the latter theory such molecular com binations are possible before the gas condenses, and thus the state of aggregation of the gas only indirectly affects the spectrum. The latter theory seems to be more consistent with experiment than the former one. For instance, it is shown that oxygen gives a continuous spectrum at the lowest temperature at which it is luminous. If the temperature be raised, the continuous spectrum is replaced by a line spectrum. This seems to be inexplicable by theory of molectlar impacts.

The chief difficulty in the way of a complete investigation of the spectrum of oxygen consists in the great disturbing influence of the presence of even a small quantity of any carbon com pound. Amongst a great many oxygen tubes which were filled by various makers I only found one, which showed the spectrum of pure oxygen; all the others gave a spectrum of carbonic oxide. It is therefore necessary in filling oxygen tubes to avoid all greased joints and all india-rubber tubings. I have used a Sprengel air-pump which communicated with the vacuum tube by means of a ball and socket joint. The joint was kept airtight solely by means of strong sulphuric acid. The vacuum tube was fused directly to the ball of the joint. To one end of the vacuum tube a piece of hard glass tubing had been fused. This was filled with different substances which, on heating, gave off pure oxygen. The oxygen, therefore, came only into contact with glass, mercury, and sulphuric acid, and the metal of the electrode. Permanganate of potash, oxide of mercury, and chlorate of potash, were used in turn, to prepare the oxygen, but no effect was observed which could be traced to the sub. stance used. The $\in$ ffect of the electrodes was eliminated by varying the metals. Aluminium, platinum, silver, brass, and iridium were used as electrodes. Any possible effect of the glass was eliminated by finally repeating all experiments in a glass receiver six inches in diameter, so that no part of the spark came nearer than $2 \frac{1}{2}$ inches to the glass. In this way it is believed all possibility of error due to the presence of any possible impurities was avoided.

Four different spectra of oxygen must be distinguished. At the lowest temperature at which oxygen becomes luminous it gives a contintous spectrum. As the temperature is gradually raised the coninuous spectrum is successively transformed into two distinct line spectra, which $I$ call respectively the compound line spectrum and the elementary line spectrum. It is one of the principal objects of this paper to show that these two line spectra which have been much mixed up together have a separate existence. The generation of one always involves the destruction of the other. The fourth spectrum is that which is always seen in vacuum tubes at the negative pole.

The Continuous Spectrom. - The following facts prove the stateinent that at the lowest temperature at which oxygen is luninous it shows a continuous spectrum. 